\title{
Assurance for MDs who refuse to assist in dying
}

$\mathrm{T}$ he Canadian Medical Protective Association (CMPA) will consider defending physicians whose ethics prohibit them from participating in advancing a patient's death, but will definitely continue to advise them on all issues.

Canada's top court overturned the ban on medical aid in dying earlier this year, giving federal and provincial legislatures until Feb. 6, 2016 to draft new laws. The court set out that physicianassisted death should be allowed for competent adults who have a "grievous and irremediable condition" that causes intolerable suffering.

In advance of these new laws, delegates at the CMPA annual meeting Aug. 26 in Halifax considered a motion to "strongly consider assisting in the defence of members in matters involving the exercise of their freedoms of conscience, religion, and professional judgment."

The motion was put forward by Dr. Todd Howlett, chief of staff at the Dartmouth General Hospital in Nova Scotia. "We're moving towards a truly patientcentred system," he told the 200-plus attendees. "To make our system stronger for our patients, we need to embrace our differences."

Before discussion opened, CMPA Executive Director and Chief Executive Officer Dr. Hartley Stern clarified the association's role. "The CMPA has and will continue to assist physicians facing legal issues. When you call for advice, we'll be here to give you advice and that includes all issues."

Despite this clarification and affirmation of assistance, the question of the CMPA's role continued to be front and centre throughout debate.

In general, those opposed to the

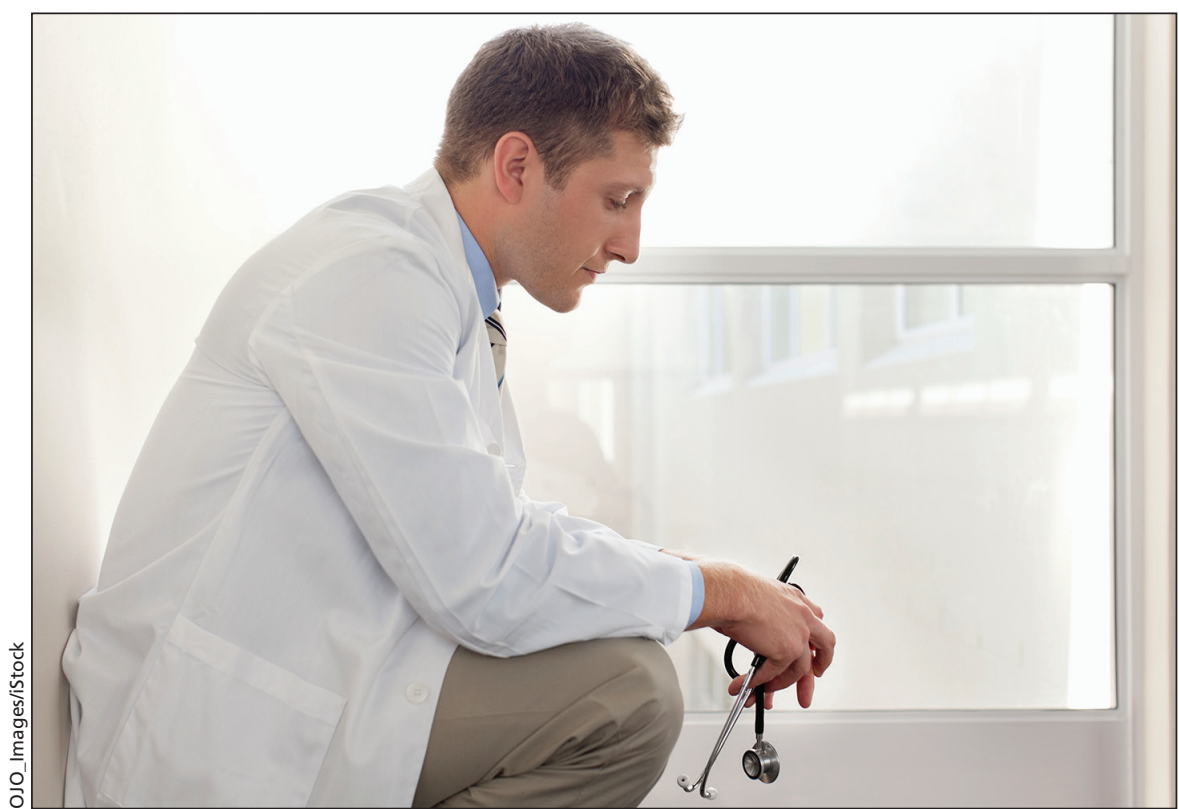

In advance of new rules, it's difficult to know if doctors will risk college reprisals if they refuse to refer a patient who wants aid in dying.

motion questioned the need to direct the CMPA in work it was already doing, or thought the motion was too broad; physician-assisted dying was not mentioned specifically.

Those in favour of the motion spoke to the importance of having official sanction and reassurance. "There is a critical need for clarity regarding what are our legal protections," one speaker said.

Specifically, several attendees asked whether doctors would be protected in the event of college reprisals if they refused, on religious or ethical grounds, to refer a patient to a doctor who would provide aid in dying.

That question and others regarding the extent of the CMPA's role went unanswered because of the absence of legislation and policy.

Stern ended the debate where it began. "We stand by the physician," he said.
A second motion approved by the delegates called on the CMPA to "engage with other stakeholders to express members' concerns about mandatory obligations that interfere with those freedoms." Delegates were assured the association currently meets with related organizations across the country, including health departments and professional colleges. However, it was made clear that the CMPA cannot dictate what those organizations will develop as legislation and policy.

Only one thing seemed certain: more debate. In his concluding remarks, Stern noted that, "This issue will likely increase the number of calls we get from 25000 to 50000 . We can safely assume there will be problems." - donalee Moulton, Halifax, NS

CMAJ 2015. DOI:10.1503/cmaj.109-5147 